\title{
Robots for Cleaning Photovoltaic Panels: State of the Art and Future Prospects
}

\section{Robots para la Limpieza de Paneles Fotovoltaicos: Estado del Arte y Perspectivas de Futuro}

\section{Marcel Tômas Grando}

Department of Mechanical Engineering -Federal University of Santa Catarina Florianópolis -Brazil marcel.grando@posgrad.ufsc.br

\section{Elias Rená Maletz}

Department of Mechanical Engineering - Federal University of Santa Catarina Florianópolis- Brazil

e.r.maletz@posgrad.ufsc.br

\section{Daniel Martins}

Department of Mechanical Engineering - Federal University of Santa Catarina Florianópolis - Brazil

daniel.martins@ufsc.br

\section{Henrique Simas}

Department of Mechanical Engineering - Federal University of Santa Catarina Florianópolis - Brazil

henrique.simas@ufsc.br

\section{Roberto Simoni}

Department of Mechanical Engineering - Federal University of Santa Catarina Florianópolis - Brazil roberto.simoni@ufsc.br 


\begin{abstract}
The growing interest in use of renewable energy sources, such as photovoltaic energy systems, occurs due to the high cost of conventional energy sources and the environmental awareness linked to renewable sources. For photovoltaic panels efficient operation, it is necessary the system presents appropriate cleaning conditions to the dirt do not obstruct the solar radiation incidence. In this context, periodic cleaning of photovoltaic panels is an obvious necessity. This work aims to present a market survey and patent analysis on the use of robots to perform cleaning tasks on photovoltaic panels. For that, the Brazilian and international literature were consulted. As a result, it was noted the existence of different solutions for cleaning photovoltaic panels, all with positive and negative aspects in practical terms. With this study it was also possible to map the technology of robotics for cleaning photovoltaic panels.
\end{abstract}

Keywords: Photovoltaic Panels, Robotics for Cleaning, State of the Art

\title{
Resumen
}

El creciente interés en el uso de fuentes de energía renovable, como los sistemas de energía fotovoltaica, se debe al alto costo de las fuentes de energía convencionales y la conciencia ambiental relacionada con las fuentes renovables. Para una operación eficiente de los paneles fotovoltaicos, es necesario que el sistema presente condiciones de limpieza adecuadas para que la suciedad no obstruya la incidencia de la radiación solar. En este contexto, la limpieza periódica de los paneles fotovoltaicos es una necesidad obvia. El objetivo de este trabajo es presentar un estudio de mercado y un análisis de patentes sobre el uso de robots para realizar tareas de limpieza en paneles fotovoltaicos. Para ello, se consultó a la literatura brasileña e internacional. Como resultado, se observó la existencia de diferentes soluciones para la limpieza de paneles fotovoltaicos, todos con aspectos positivos y negativos en términos prácticos. Con este estudio también fue posible mapear la tecnología de la robótica para la limpieza de paneles fotovoltaicos.

Palabras claves: Paneles fotovoltaicos, Robótica para la limpieza, Estado del arte

\section{INTRODUCTION}

Due to the increased cost of conventional energy and its harmful effects on the environment, the use of renewable energy systems has attracted much attention in recent years [1]. Among them are systems for generating energy from sunlight.

Farenbruch and Bube [2] highlight the potential of this type of energy, since in human species longevity tercos, the Sun's life is effectively infinite. According to the authors, there are many ways to use solar energy. In thermal-solar systems, for example, the heat from the radiation is used in the forro of heating, directly. On the other hand, in the case of photovoltaic systems, solar energy is converted into electricity [2].

In photovoltaic systems, electronic devices known as pho-tovoltaic cells are positioned 
on panels exposed to sunlight and transform the energy through the electron flow between two layers of semiconductors [3]. Therefore, for photovoltaic cells to be operated at their maximum efficiency without loss of energy, it is necessary that the photons have free access to the photovoltaic cells of the photovoltaic panel. However, it is known that some external agents, such as the presence of clouds and the deposit of dust on the surface of the panels, are responsible to obstructing the integral access of sunlight to the system [3]. Experiments performed on solar parks, for example, show that the efficiency of a photovoltaic panel can decrease by up to $40 \%$ due to accumulation of residues on the surface [4].

Thus, in terms of accumulation of dirt, in order to maintain the photovoltaic panels energy efficiency, it is evident that periodic cleanings are required on the surface of them. Researches conducted in southeastern America indicates that in about 8 weeks, in the absence of cleaning procedures, the accumulation of dirt on the surface of the panels is responsible for the drop of about $6.9 \%$ in system performance. When the cleaning is performed once in a year, the same research pointed out that there is a recovery of only $0.81 \%$ on the capture of solar energy and when the cleaning procedure is performed regularly, there is a positive impact of $9.8 \%$ on the capture [4]

Considering the periodic cleaning of photovoltaic panels, practical and efficient solutions have been developed over time to enable them to maintain their energy capacity [5]4111

In this direction, this paper aims to present the state of the art related to the alternatives for cleaning photovoltaic panels in the scope of robotic technology.

\section{METHODOLOGICAL PROCEDURE}

The work described in this article presents a review on the use of robots for cleaning photovoltaic panels. The review was divided into two parts, the first one reviewing available products in the market and the second part being composed by the technological survey, using patent search.

Market review is an important step on conducting the survey on a particular technology. Through the perception that they are as technologies and as tendencies of evolution of the methods used for the solution of the problems.

In this sense, the research of available products was carried out both in the national (Brazilian) and in the international market. In order to assist in market search conducted, Google search software, and article and periodical portals such as capes, science direct, IEEE digital library were used.

The market search was performed primarily focusing on the national market (Brazilian market) using the portuguese keywords "limpeza", "painel fotovoltaico" and "robó". For the international market, the main key words were the same, but translated into English, which were "cleaning", "photovoltaic panel" and "robot".

The criteria used for selecting products and cleaning meth-ods was the availability of catalogs online consultation and datasheets. After defining the search criteria, the selected products were studied and detailed according to the specifications provided by their manufacturers.

For the review of patents the methodology presented by [12] was used by performing the following steps:

1) Preliminary Patent Search - This step aims to conduct an initial survey of available patents. For this search was used the Espacenet database [13]. The generic keywords used 
were: "photovoltaic panel", "photovoltaic panel", "cell array", "clean", "brush", "robot" and "device".

2) Preliminary search analysis - At this stage the patents previously searched are analyzed by looking at words that most relate to the subject and their main IPC's.

3) Detailed search - At this stage the IPC's identified in the previous step are combined with the new keywords, so the results that do not apply to the focus of this work are not returned in the searches.

4) Analysis of the detailed research - Finally, in this step, although the number of results is smaller when com-pared to the quantity returned by Step 1, the contents of all the patents are, to a certain extent, related to the theme searched in this work. Thus, after filtering the search results, the contents of the selected patents are analyzed.

\section{RESULTS AND DISCUSSION}

This section will present the results obtained with the market and patent search. In the market search, the main solutions returned by the searches are discussed, as well their methods of cleaning and the technologies employed by each solution in the context of cleaning photovoltaic panels.

After the market search is presented the discussion of the patent search. In addition to detailing the method used in the patent search, the context in which the patent was submitted and the methods used for cleaning photovoltaic panels are discussed.

A. Market

In this section will be exposed some of the available commercial solutions to the cleaning photovoltaic panels.

1) Solarbrush UAV Robot: The Robot UAV Solarbrush, until now, perforrns the cleaning of the solar panels in a unique way, as shown in Figure 1.

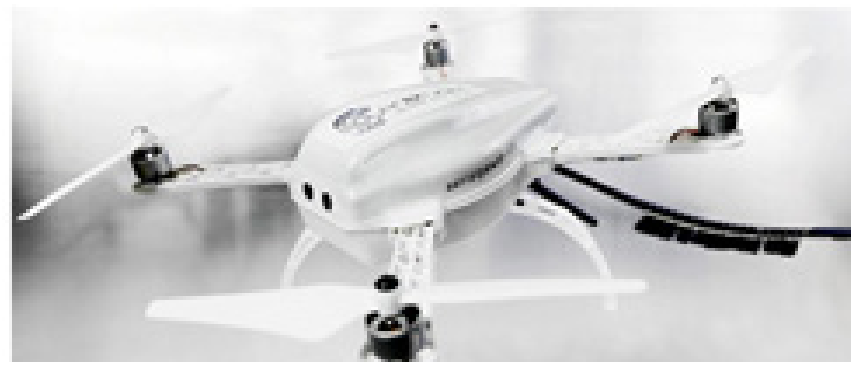

Fig. 1. Solarbrush UAV Robot. Source: [6].

This robot performs the cleaning of the photovoltaic panels through the air. The Solarbrush $\mathrm{UAV}$ is a drone that is composed of 4 sets of propellers and a tail, which has a specific material to perform the cleaning of the panels.

The only part of the drone that makes contact with the surface of the photovoltaic panel is its tail, which according to its developers, is the main advantage of using this robot, since with this feature the chances of damaging the photovoltaic panel decrease [6].

2) Ecoppia E4: Ecoppia E4, as can be seen in Figure 2, is a fully autonomous robot that uses microfiber brushes to sweep the dust from the panels. It is designed for large rows of panels located in dry and sandy environments. The robot uses a photovoltaic panel and battery on board to store energy, this allows the robot to perform cleaning at night and the positioning of the photovoltaic panel at the bottom of the rail allows it to be cleaned by the 
robot itself.

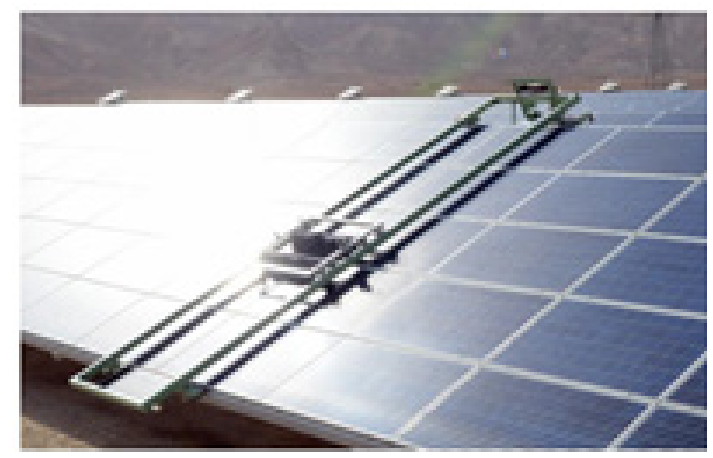

Fig. 2. Ecoppia E4 Robot. Source: [7].

The movement of the robot occurs through a guide rail fixed to the edge of the photovoltaic panel. In addition the robot has remote access, where cleaning commands or cleaning statistics can be obtained from any equipment connected to the internet. Finally, the robot has an intelligence programmed to perform cleanings according to the climatic conditions [7].

3) Washpanel: The Italian company called WashPanel produces robots that clean arrays of photovoltaic panels by moving a vertical brush horizontally over an array of panels. The length can vary from 1 to 16 meters. The robot has coupled a water hose to wet the panels during cleaning, as can be seen by the robot shown in Figure 3 [8].

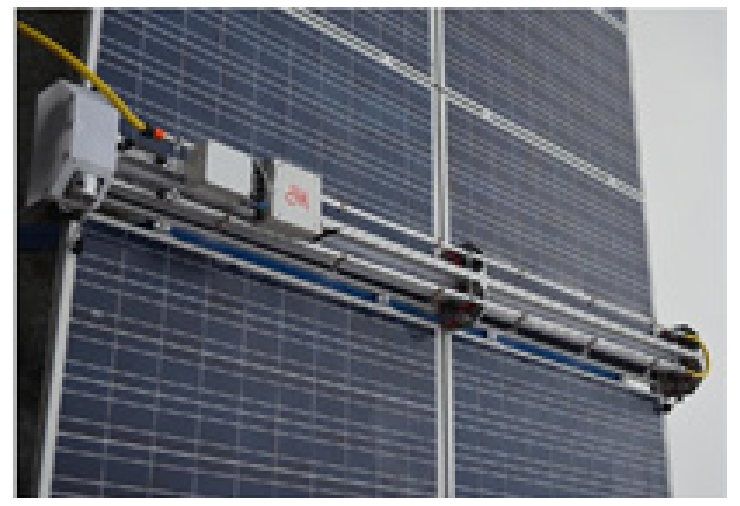

Fig. 3. Washpanel Robot. Source: [8].

The Washpanel robot has an interface where it is possible to program the washing system, it has a battery system with automatic load to carry out the movement. It also has rain, voltage and anemometer sensors.

4) NOMADD Cleaning System: Like the previously men-tioned Ecoppia E4 robot, the NO Water Mechanical Auto-mated Dusting Device (NOMADD), shown in Figure 4, is a robot designed specifically to remove dust accumulation from the photovoltaic panel arrays of the desert without the use of water. 


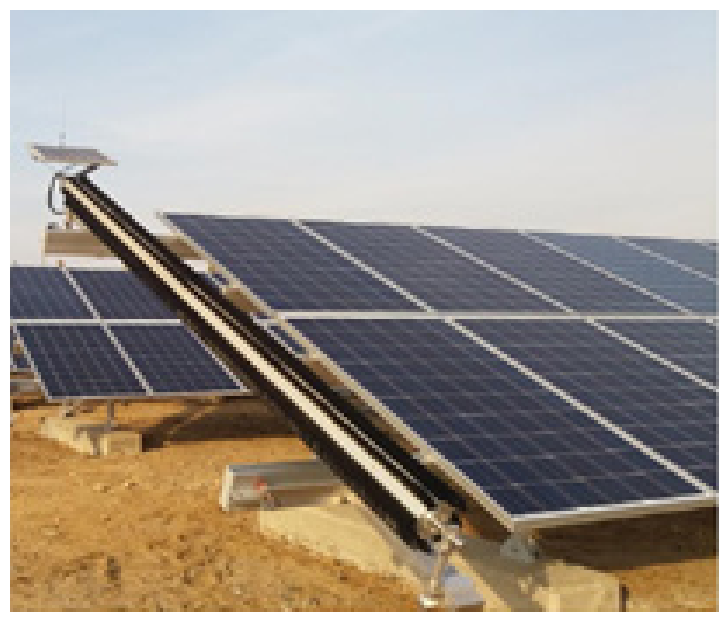

Fig. 4. NOMADD Cleaning Robot. Source: [9].

In addition to not using water for cleaning photovoltaic panels, the NOMADD robot presents some features such as your own solar panel, fully automated and remotely controlled operability, capable of surviving adverse conditions due to its robustness and is capable of cleaning an array of photovoltaic panels [9].

5) Other cleaning methods: Besides the cleaning methods perforrned by robots explained earlier, other methods of cleaning photovoltaic photovoltaic panels are used in some situations, which are the nonautonomous methods.

These nonautomated methods can be employed in two ways, where the first one is with the use of sprinklers, as shown in Figure 5.

Sprinkler systems are often used in dry creas to keep panels clean. It has the same cleaning effect as the rains and cleans the panels at a relatively low cost. As the majority of systems, the one presented by Heliotex [10], consists of a water filtration system and soap dispensing system. The company also advise

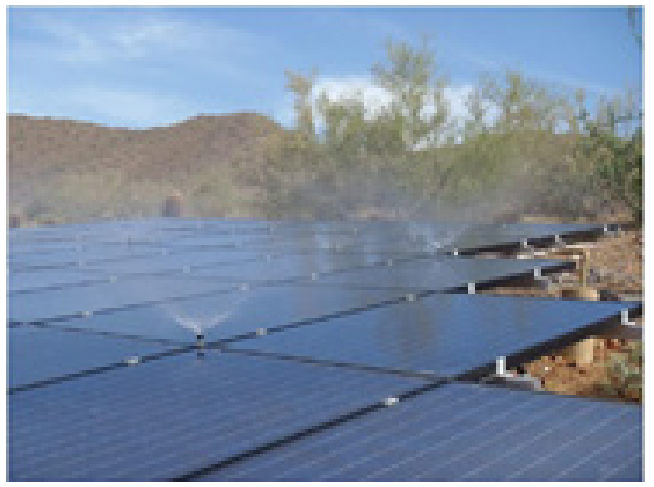

Fig. 5. Sprinlders used for cleaning photovoltaic panels. Source: [10].

that water quality should be tested and, optionally, a water treatment is advisable for locations with untreated water. 
Although this is a relatively good work system, there are some disadvantages. First of all, it uses a lot of water because it cleans the panels several times a day depending on the schedule. This is necessary because, as the panels get dirtier, it becomes more complicated for the sprinklers to remove all the dirt. Secondly, both the filters and the level of soap should be monitored and taken care of, and this ends up costing a lot of time and money.

And finally as the last cleaning method discussed in this paper, there is the manual method, which is the most used method for cleaning of residential photovoltaic panels. Using a handle with a connected water hose and a brush that does not scratch the panel, the cleaning is performed, as shown in Figure 6 [11].

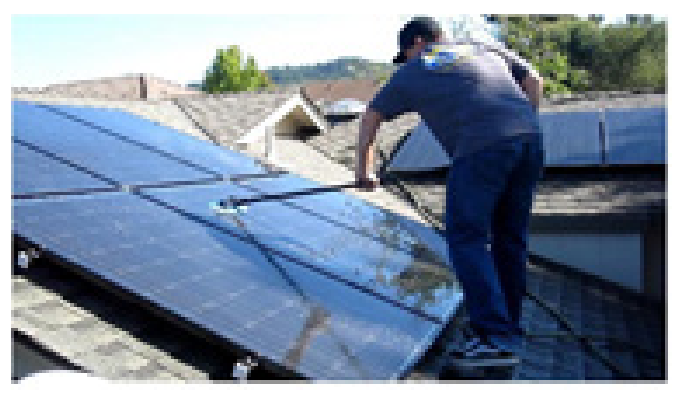

Fig. 6. Manual cleaning of photovoltaic panels. Source: [14].

This cleaning method exposes operators to risks such as climbing stairs and climbing rooftops. If this work is con-ducted by a specialized company, it can have a high investment, since the costs to perform this type of cleaning are usually high.

B. Patents

Granted by the State and based on the Industrial Property Law, a patent is a temporary right over an invention or an utility model. This means that it is a legal instrument of protection and allows a number of benefits or advantages to the inventor or assignee, thus rewarding the technological innovation and creative industry [15].

The patent survey is a very important step in the creation of new technologies and/or products. Because through the search is possible to investigate the technological state and possible gaps. Based on this statement this subsection discusses the patent survey for the cleaning problem of photovoltaic panels.

From the patent preliminary survey, the main IPC's were identified, being: BO8B 1/04, BO8B 13/00, HO2S 40/12, A47L 11/38, A47L 9/28 and EO1H1 / 00. Where BO8B means cleaning in general; prevention of fouling in general, the subindex 1/04 means using rotary operative members and the subindex 13/00 identify accessories or details of general applicability for machines or apparatus for cleaning.

The índex HO2S means generation of electric power by conversion of infrared radiation, visible light or ultraviolet light, eg using photovoltaic [PV] modules, the subindex 40/10 and 40/12 means cleaning arrangements and means for removing snow, respectively. Already the IPC A47L means cleaning windows, window shades, window screens, venetian blinds, the subindex 11/38 identify Machines, specially adapted for cleaning walls, ceilings, roofs, or the like and the subindex 9/28 means Installation of the electric equipment, eg adaptation or attachment to the suction cleaner; Controlling suction cleaners by electric means.

Finally, the IPC EO1H means street cleaning; cleaning of permanent ways; cleaning 
beaches; cleaning land; dispersing fog in general and the subindex $01 / 00$ means removing undesirable matter from roads or like surfaces, with or without moistening of the surface.

The main keywords found in the preliminary survey were divided into three groups to perforen the detailed survey:

- What should be cleaned - flat surface, planar surface, solar panels, photovoltaic panels, PV panels and cell array.

- What is the function to perform - clean, maintenance, brush, wash, mop and wipe off.

- What is the object that would perforen the function apparatus, robot, device.

From these survey groups, the words of each group and the IPC's were combined to do the search on Espacenet database. In the searches performed, the words combination should be in the abstract or title and be classified into one of the following IPC's: B08, H02, A47 or E01 or in its subindex. The Boolean operator "*" was still used for the words related to the function (this operator seeks for different terms that have the same radical).

With the groups of words generated the searches were performed, totaling 4221 results. Although IPC's were used to direct the search, a large number of results were obtained. Combinations that returned a significant number of results are shown in Table 1.

\begin{tabular}{|c|c|c|}
\hline Index & Combinations & Number of results \\
\hline 1 & solar panel + clean* + device with & 816 \\
\hline 2 & flat surface + clean* + device & 551 \\
\hline 3 & solar panel + maintenance + device & 309 \\
\hline 4 & solar Panel + brush* + device & 265 \\
\hline 5 & flat surface + clean* + apparatus & 239 \\
\hline
\end{tabular}

TABLE 1: COMBINATIONS WITH MORE RESULTS

Analyzing the detailed survey there was large number of results with the tercos: device, solar panel, flat surface and clean*. In the combinations flat surface + clean $^{*}+$ device and surface flat + clean* + apparatus were observed many patents unrelated directly with solar panels, but which could be adapted.

To illustrate the analysis of detailed survey and present the different patented methods from cleaning solar panels are presented below the analysis of some patents.

Cleaning robot solar cell panel - CN 106000955 (A)

The patent in question is of Chinese origin, deposited in 2016, it is classified with the IPC's BO8B1 / 04, BO8B13 / 00, HO2S40 / 10, HO2S40 / 12. This patent discloses a system set in an array of photovoltaic cells (Figure 7(a)) which carnes out the cleaning there of by a brush system (Figure 7(b)) which rotate and carry out dry cleaning of deposited dust on the solar panel. Besides the vertical movement described aboye, the robot present panning control enabling interaction between the brushes and the panels. 

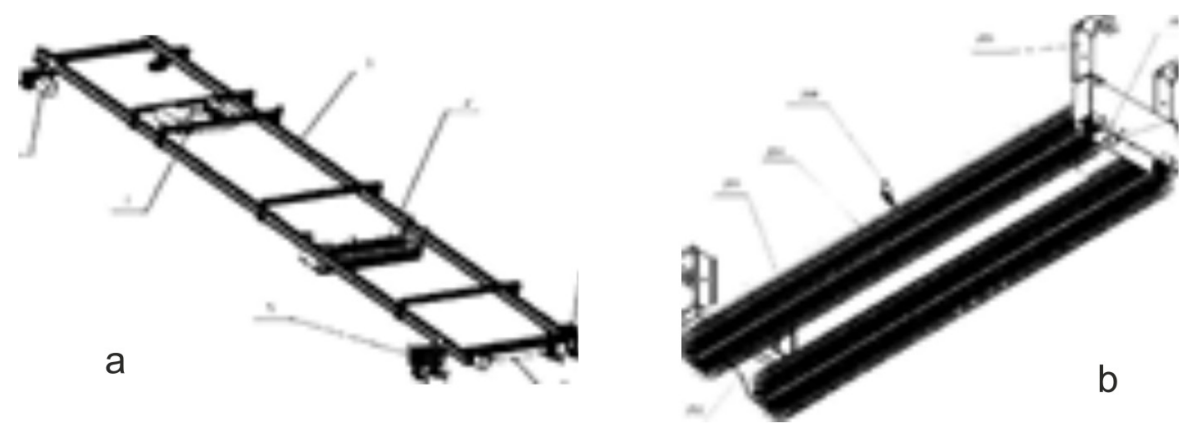

Fig. 7. (a) Robot structure and (b) Brush. Source: [16].

- Waterless cleaning system for intelligent cleaning robot - CN 106026891 (A)

Patent of Chinese origin, was deposited 2016 and the following IPC's BO8B1 / 04, HO2S40 / 10 .

The robot described in this patent also performs cleaning of the dry solar panels with a set of brushes, but the brushes used in the assembly is coupled serially and allows the surface cleaning slightly nonplanar, as illustrated in Figure 8(a). However, the robot doesn't have vertical movements, in the case where the robot has a array greater than height to carry out cleaning, it has to go through more than once the same array to get clean it completely. The Figure 8(b) illustrate the grooves in an array not flat, allowing the horizontal movement of the robot.


Fig. 8. (a) Robot and (b) grooves in array not flat. Source: [17].

- Dust removing robot used for solar cell panels CN 106362977 (A)

Chinese Patent deposited in 2017 identified by the IPC's BO8B1 / 00, BO8B1 / 04 and H02S40 / 10.

The robot presented in this patent use a different drive method of others, that is through suction cups. This drive method allows greater freedom for the created robot, it can move 
in both directions, horizontal and vertical. The robot in question is illustrated in Figure 9.

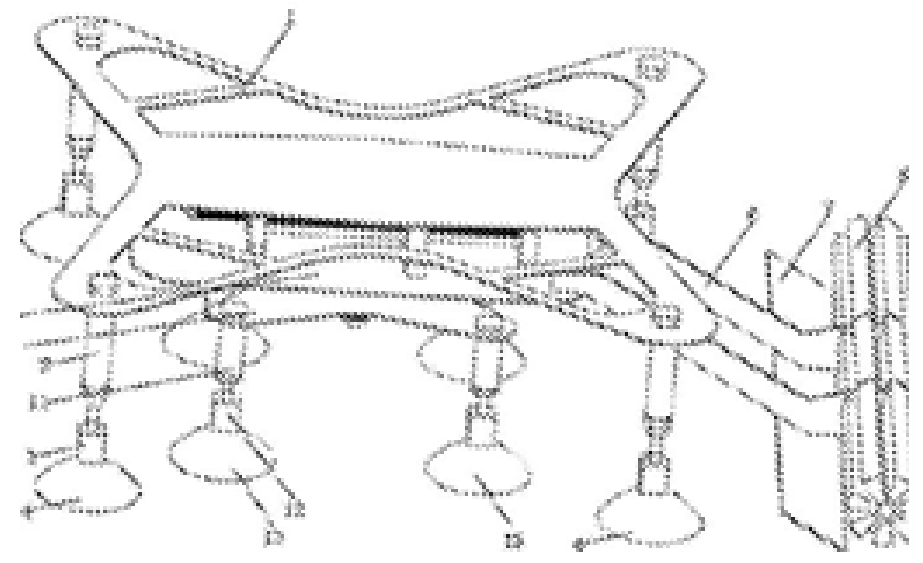

Fig. 9. Photovoltaic panel cleaning robot. Source: [18].

The robot cleaning method can be view from Figure 9, this robot also provides cleaning method dry with rotary brushes, as well as other robots so far presented.

. Solar Panel Auto Cleaning Robot Apparatus - KR 101623460 (B1)

The patent is of Korean origin, was deposited in 2016 and classified with the IPC's BO8B 11 / $00 \mathrm{H} 02 \mathrm{~S} 40$ / $10 \mathrm{E} 01 \mathrm{H} 1$ / 00.

In this patent it is possible to observe a solar panel cleaning method using a robot coupled in the manipulator installed in one vehicle, as can be view in Figure 10(a).
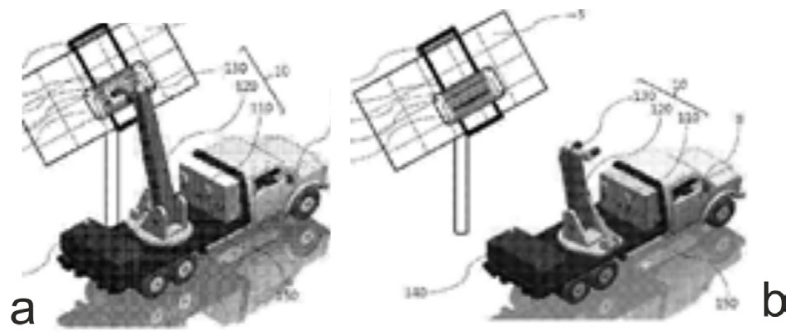

Fig. 10. (a) Cloupled robot and (b) Robot Decoupled robot [19].

To perform cleaning the vehicle is approach the at the panel to be cleaned, a array is mounted on the solar panel and the robot is coupled to the array and decoupled from the manipulator, as can be seen in Figure 10(b).

When decoupled from the manipulator, the robot performs cleaning through a water jet, movement vertically and horizontally over the panel.

The robot also includes detection sensors installed at each end for detect the cleaning robot position and sensors measuring the level of dirt present on the solar panels. 


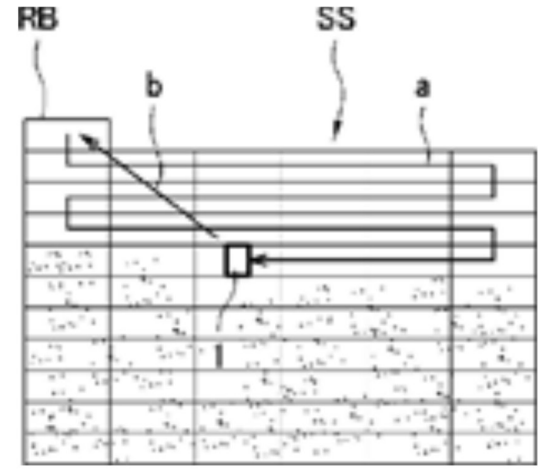

a

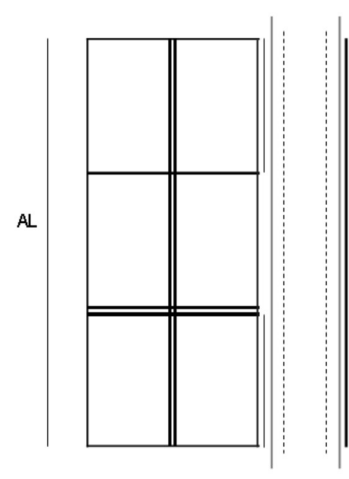

Fig. 11. (a) Cleaning robot of various panels and (b) large cleaning robot [20].

\section{FUTURE PROSPECTS}

With the mapping of photovoltaic panel cleaning robots, we realize the existing solutions basically consists of the moving the robot in array of panels. This mapping revealed that some fields may be exploited, such as aerial robots, actuated by cables, suction cup, among others.

According to the technology review and robots found in the survey it is possible to realize that aerial robots have a very high complexity to perform their control since it is necessary to perform both the position control and the control of the force that the robot exerts on the solar panel to perform the cleaning. On the other hand, the robots that perform the suction movement have a very low mobility and due to their low mobility the cleaning of the panels becomes slow, not proving to be an interesting alternative for the cleaning of solar parks.

Due to the gaps in the development technology of solar panel cleaning robots presented in this work, some proposals for solutions are presented, which have a high degree of innovation and applicability, and can encourage the development of products in the market for renewable energy sources.

Among the technology gaps that have been presented in this work, some research perspectives involve the development of a manipulator robot coupled in a fixed guide in an array of solar panels that performs the cleaning of the panels with vertical movements. A second perspective that may be pointed out for research is the use of cabledriven robots to perform the cleaning of an array of solar panels.

These two research perspectives present characteristics that the other solutions found do not have, one of them is the use of a manipulator that moves by rails and the second involves the use of the concept of cabledriven robots. This second research perspective does not have antecedents yet as shown in the review presented in this work and is also a concept that has a very high adaptability and can be configured to clean from small to large solar parks.

In addition to the previously proposed prospects for the solar panel cleaning system, as this is an emerging technology in Latin America the cleaning method is something that has 
a great potential to be explored too, since there are many types of dirt and optimal removal methods for each type of dirt are different.

\section{CONCLUSION}

The efficiency of photovoltaic panels is directly affected by dirts that are deposited on them. Therefore, the periodic cleaning of the panels is a necessary task in order to they operate at maximum efficiency.

Being this a pioneering revision in the area of technologies of cleaning photovoltaic panels, were found on the market different cleaning solutions for various types of dirt, but the most used is dry cleaning for solar parks where the source of photons obstruction consists mainly of sand and dust, other cleaning method use water for the removal of the dust and some other types of dirt that do not come out as easily.

The vast majority of cleaning methods consists of mop the panels with a set of driven brushes in different ways, but other forms of cleaning with lower efficiency were showed, could be cited the dust removal method with water jets applied to the panel surface.

It was also observed that the great majority of patents and solutions found in the market, use rails in the solar panels to perform the movement of the cleaning system. Larger cleaning systems (the size of a frame) use only one rail for horizontal movement, while the smaller systems also use a vertical rail for the system to make horizontal and vertical movements on the panels surface.

Through the technological mapping with the systematic patent survey there are solutions that are not exploited to their maximum potential, such as the research perspectives pointed out previously, which are the robot manipulator coupled in a fixed guide and the cabledriven robot for cleaning solar panels. Another gap noticed with the technological mapping is related to the cleaning methods, since there are different optimal methods for cleaning different types of dirt and these methods are not yet explored. 


\section{REFERENCES}

[1] N. Hamidreza; N. Behzad. Sensitivity analysis of a hybrid photovoltaic thermal solar collector. 2011 IEEE Electrical Power And Energy Conference, p.1-6, out. 2011.

[2] E Alan; B. Richard. Fundamentals Of Solar Cells: Photovoltaic Solar Energy Conversion. Londres: Academic Press, 2012. 559 p.

[3] A., Mark et al. Robotic device for cleaning photovoltaic panel arrays. Mobile Robotics,World Scientific, p.1-11, ago. 2009.

[4] K., Matthias. The development of a cleaning robot for PV panels. 2014. 65 f. Master Thesis - Curse of Engineering Technology, Technology Campus de Nayer, Ku Leuven, Leuven, 2014.

[5] L., Lisa A.; C., Lana El. Enhancement of a stand-alone photovoltaic system?s performance: Reduction of soft and hard shading. Renewable Energy, Elsevier BV. v. 36, n. 4, p.1306-1310, abr. 2011.

[6] AERIAL POWER LTD (Londres). The world?s first fully automated UAV for cleaning solar panels. Available at: <https://www.aerialpower.com/solarbrush/>. Access at: 11 jun. 2017.

[7] ECOPPIA 1ND (Herzlia). Ecoppia: Technology. Available at: <http://www.ecoppia. com/technology/>. Access at: 10 jun. 2017.

[8] WASHPANEL S.R.L. (Villorba). Prodotti Washpanel. Available at: <http://www. washpanel.com/prodotti.php>. Access at: 10 jun. 2017.

[9] NOMADD (Arbia Saudita). The NOMADD Cleaning System. Available at: <http:// www.nomaddesertsolar.com/the-nomadd-technology.html>. Access at: 11 jun. 2017.

[10] HELIOTEX (California). Residential So-

lar Panel Cleaning Services. Available at: Ghttp://www. solarpanelcleaningsystems.com/ residential.html> . Access at: 10 jun. 2017.

[11] SOLARVOLT ENERGIA (Minas Gerais). Aprenda a realizar a manuteno de sistemas solares fotovoltaicos. Available at: Ghttp://www. solarvoltenergia. com.br/aprenda-arealizar-a-manutencaode- sistemas- solares-fotovoltaicos/> . Access at: 11 jun. 2017.

[12] T. Hoeltgebaum. Variable Compression Ratio Engines: A mechanism approach. Master Thesis - Federal University of Santa Catarina, Florianpolis, Brazil. 2016.

[13] ESPACENET. Patent Search. Available at:

http://worldwide.espacenet.com/. Access at: Julho de 2017.

[14] WESTCOAST SOLAR ENERGY (Califor-

nia). Operations and Maintenance. Available at:

$<$ hhttp://www.westcoastsolarenergy.com/maintenance/>. Access at: 11 ago. 2017.

[15] E Gomes. Protegendo sua inveno. 2017. Available at: <http://fgmarcas.com.br/ entenda-a-importancia-das-patentes-para-aindustria-criativa-2/>. Access at: 25 jun. 2017. 
[16] L. Zhang, W. Zhang, C. Zhang, H. Pan, K. Yuan, J. Jiang, Cleaning robot for solar cell panel, CN patent 106000955 (A), to Qingdao Sarnath Intelligent Tech CO LTD., Patent and Trademark Office, Pequim, 2016.

[17] L. Mingyang and W. Meng, Waterless cleaning system for intelligent cleaning robot, CN patent 106026891 (A), to Beijing Hit Robot CO LTD and Beijing Chuangshi Jieneng Robot CO LTD, Patent and Trademark Office, Pequim, 2016.

[18] G. Hengxiang and Z. Kangqu, Dust removing robot used for sollar cell panels, CN patent 106362977 (A), to UNIV Chongqing Tech, Patent and Trademark Office, Pequim, 2016.

[19] H.Tae Gyu and C. Jin Hun, Solar panel auto cleaning Robot Apparatus, KR patent 101623460 (B1), to UNIV Chongqing Tech, Patent and Trademark Office, Pequim, 2016.

[20] M. Tohru and M. Hideto. Autonomous-travel cleaning robot, US patent 2015272413 (Al), to Miraikikai 1NC, Patent and Trademark Office, Washington, D.C., 2015. 